\title{
Multi-Hazard Zonation For Effective Management of Disasters in Tamil Nadu
}

\author{
A. Balasundareshwaran ${ }^{1}$, K. Kumaraswamy ${ }^{2}$ and K. Balasubramani ${ }^{1^{*}}$ \\ ${ }^{1}$ Department of Geography, Central University of Tamil Nadu, Thiruvarur, Tamil Nadu - 610005, India \\ ${ }^{2}$ Department of Geography, Bharathidasan University, Tiruchirappalli, Tamil Nadu - 620024, India \\ *Corresponding Author: geobalas@cutn.ac.id
}

Received 6 February 2020/ Revised 16 February 2020/ Accepted 1 March 2020/ Published 10 April 2020

\begin{abstract}
Natural hazards are a long existing threat to human and their surroundings which may occur throughout the world. Tamil Nadu is one of the Indian States with a number of natural hazard incidences. The occurrence of natural hazards, such as cyclone, storm surge, flood, drought, landslide, forest fire etc., has increased manifold in the recent decades.The multi-hazard zonation is one of the preliminary studies in disaster management scenario, which is used to understand the product of all prominent natural hazards. At the state level, it is imperative for the government to know the regions affected by multiple hazards to help them prepare the management plans appropriately to protect the local communities and infrastructures. However, such systematic hazard assessment and integration in an administrative unit is largely missing in Tamil Nadu. Further, the utilisation of geoinformatics in the preparation of multi-hazard zonation helps to identify the most endangered areas of the State precisely and offers insights to detailed studies in highly risk zones. This paper attempts on these lines to prepare Multi Hazard Zones (MHZ) based on natural hazards viz. earthquake, landslide, cyclone, storm surge, flood, drought and forest fire of Tamil Nadu. The data for the study were generated from multiple sources, which were all generalised and integrated in a normalised scale. The occurrences, intensities and frequencies of hazards, namely seismic, landslide, and forest fire are the reasons for a very high multi-hazard in hilly tracts of the Nilgiris and parts of Shayadhri hills in Coimbatore and Theni Districts, whereas cyclone, storm surge, and flood caused a very high risk along the coastal stretch of Chennai, Kancheepuram, Cuddalore and Ramanathapuram Districts. The segregation of the results into administrative division's which was then categorised in an order of high risk zones may provide a powerful tool to the State authorities to allocate fund and resources. The output of this study also offers zonation for immediate knowledge, policy briefs, and proper disaster management plan at State level.
\end{abstract}

Keywords : Disaster Management; Natural Hazards; Geoinformatics; Tamil Nadu

\section{Introduction}

According to the disaster statistics from UNDP's Disaster Risk Reduction Programme (2012), the average disasters per year have increased for more than 60 per cent in the last decade. 
A. Balasundareshwaran et al / GEOSI Vol 5 No 1 (2020) 65-79

Asia has the highest number of victims due to natural disasters. It is not peculiar at all that the increase in the frequency of disaster, its magnitude, complexity, economic impact and number of deaths, registers in the low human development region and less prepared communities. According to the NDMA (2016), hazards pose threats to people and assume serious proportions in the under developed countries with dense population. The regional study of hazards helps us understand the influencing factors, analysing them without exclusion of nearby quantifiable factors, provides applicable regional alike solutions. There is a coarse approach followed in disaster plans at state and local level in India where national level zonation considered for all kinds of disaster risk management without detailed regional or local attempts.

Tamil Nadu, the southern-most State of India, nestles in the Indian peninsula between the Bay of Bengal in the east, the Indian Ocean in the south, and the Western Ghats and the Arabian Sea on the west. In the north and west, the State adjoins Karnataka, Andhra Pradesh, and Kerala (Figure 1). The eastern extremity of the State is Point Calimere situated at $80^{\circ} 20^{\prime}$ E longitude, while the western tip is the Mudumalai Sanctuary at $71^{\circ} 15^{\prime}$ E longitude. The northern and southern extremities are defined by Pulicat Lake $\left(13^{\circ} 35^{\prime} \mathrm{N}\right.$ latitude) and Cape Comorin in Kanyakumari $\left(08^{\circ} 50^{\prime} \mathrm{N}\right.$ latitude). An effective disaster management program always requires a detailed hazard zone, which is largely omitted in the State. At the same time, natural hazards that rattle the vulnerable communities of Tamil Nadu are increasing manifold and often occur simultaneously. The natural hazards of Tamil Nadu occur mostly isolated with seasonal characteristics and seldom occured all together that poseda maximum threat in a combined form within the same region.

Drought is considered one of the reoccurring disasters of Tamil Nadu, which hampers the development of the region. Even though drought is non-structural, it spreads over a larger geographical area and posesmore serious threats to population than the resultsof other natural hazards such as floods, tropical storms, and earthquakes (Balasubramani, 2014). Balasundareshwaran, et al., (2019a) evaluate drought within an administrative unit and suggested that, the drought restricts the growth of a region. Similarly debated that, flood both gains and losses, where it either sweeps the entire regions or deposits minerals for next seasonal irrigation. Likewise, cyclones bring in gusty winds to the coastal parts of Tamil Nadu, especially during the north-east monsoon season (October-December), which influence the sea level to swell and cause coastal inundation, storm surge, and flooding in the inland rivers where the impacts are multi-fold (Ramkumar, 2009). A spatio-temporal pattern of earthquake occurrences in South India was epitomised by Gangai et al., (2009) who revealed that seventy-seven occurrences of earthquakes with magnitude above 3.0 were recorded within and adjoined regions of Tamil Nadu in the last two centuries. Ramkumar (2019) argues that the net effects of tectonic quiescent regions and 
A. Balasundareshwaran et al / GEOSI Vol 5 No 1 (2020) 65-79

geomorphometric processes induce the earthquake occurrences in Tamil Nadu. Natarajan, et al.,. (1988) studied the landslides of the Nilgiri regionand described that the deforestation had resulted into massive soil erosion along the slopes, which increased the seepage and ,thereby, resulted into an increase in pore pressure leading to landslides in many hilly topography of the State. Further, forest fire (wildfires) also increases the air pollutants and the instantaneous concentration of particulate matters in the atmosphere during the fires and poses serious health risks (Sofowote \& Dempsey, 2015).

Geoinformatics aids in identification, demarcation, assessment, and management of hazards. Nowadays, geoinformatics plays a key role in extracting potential information from an extensive region or inaccessible location. Satellite remote sensing has successfully proven itself as a valuable information generator for various hazards studies (Bhanumurthy et al., 2010). Almost all of the natural hazards that can be studied are mapped with the help of geoinformatics. Many studies proved that the utilisation of geoinformatics increases the value of datasets as highly reliable, accurate, and cost effective. Many attempts, including Behanzin et al., (2015), Roy and Blaschke (2015); Shankar et al., (2015); Udo (2015); Udani \& Mathur (2016); Prasad \& Narayanan (2016); Hoque (2017); Oluwasegun (2017); Chigbu et al., (2018); Sharma et al., (2018), help us to understand the hazard scenario of the State. However, the integration of multi-hazards and delineation of accurate zones using geoinformatics is still missing in Tamil Nadu. Even though arguably the hazard hotspot regions covers the coastal and urban regions (Shrinarayan, 2015; Balasundareshwaran et al., 2019), MHZ covering the entire State with reliable datasets is still scarce. Hence, the present study attempted to identify the multi-hazard prone zones of Tamil Nadu and showcase the use of geoinformatics in a systematic hazard assessment.

\section{Methods}

The research primarily deals with the use of geoinformatics in MHZ for Tamil Nadu. In the initial phase, the spatial and temporal dimensions of natural hazards of Tamil Nadu were examined. All the possible natural hazards were considered and ranked according to the occurrence and impacts in the past, namely drought, flood, cyclone, storm surge, earthquake, landslides, and forest fire. 
A. Balasundareshwaran et al / GEOSI Vol 5 No 1 (2020) 65-79

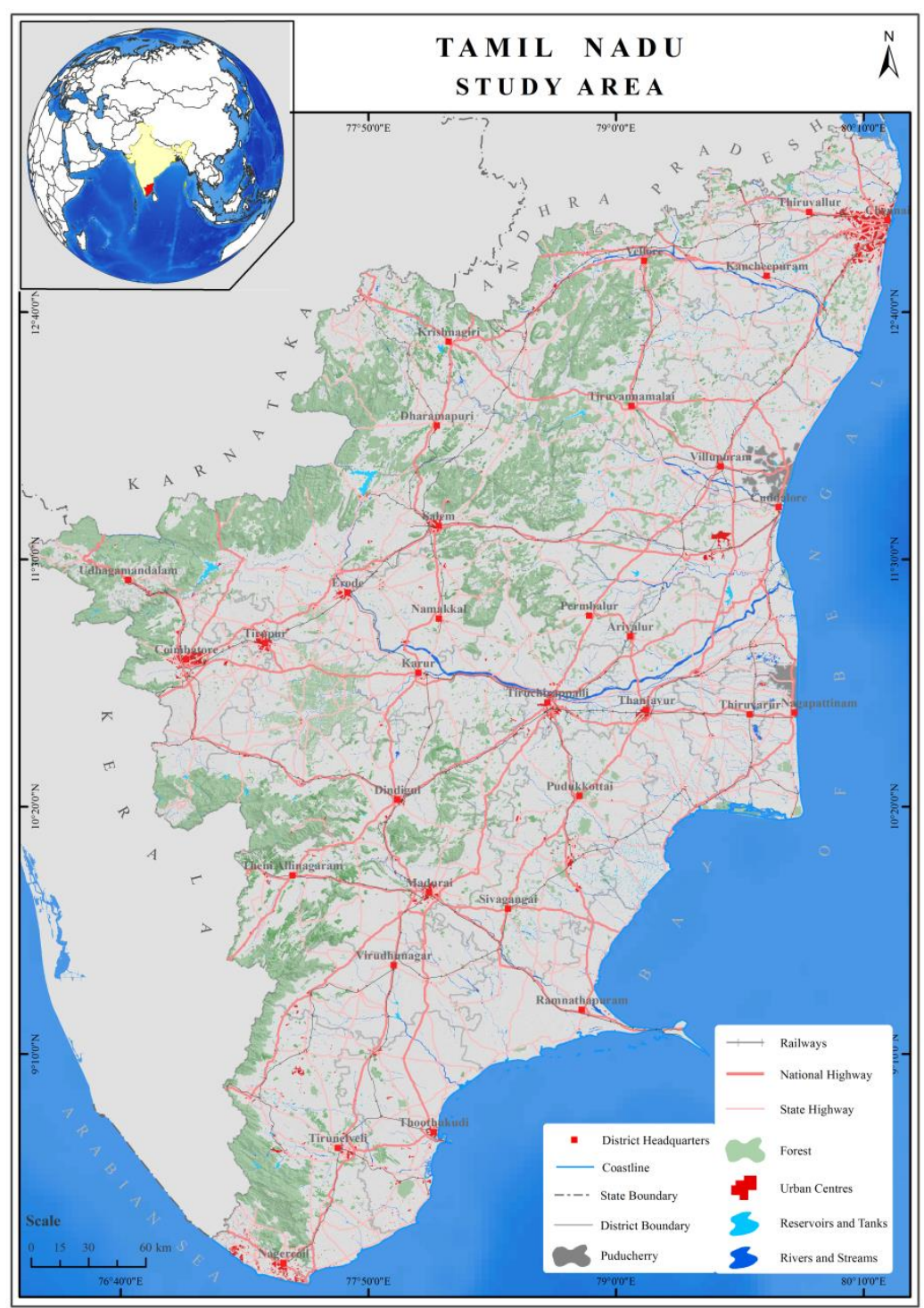

Figure 1. Location and Study Area of Tamil Nadu

The drought datasets used for the study, mainly comprised of three categories (1) meteorological records acquired from ground stations, (2) products derived from the satellite sensors, and (3) ancillary data from various sources. High temporal satellite datasets considering vegetation, temperature, and precipitation were used to compute proxies for drought hazard assessment viz. Precipitation Condition Index (PCI), Temperature Condition Index (TCI) and Vegetation Condition Index (VCI). Terra MODIS surface reflectance MOD13Q1 (250m) (20002016) used for VCI, MODIS LST of MOD11A2 (1km) (2000-2016) was for TCI and TRMM 3B43 $\left(0.25^{\circ} \times 0.25^{\circ}\right)$ precipitation estimate (2000-2016) was used for PCI. Finally, the Scaled Drought Condition Index (SDCI) - a multi-sensor drought index proposed by Rhee et al. (2010) was used to calculate composed drought index as given in the equation:

$$
S D C I=0.25 T C I+0.5 P C I+0.25 V C I
$$

The low values of SDCI imply serious condition of drought. Under a drought process, the SDCI is close or equal to 0 and at wet conditions the SDCI is close to 1 . 
The cyclone hazard was assessed by utilising the Geographic Information System (GIS) through a long-term best tracks cyclone database from Indian Meteorological Department (IMD) and Joint Typhoon Waring Center (JTWC) of Bay of Bengal for the period of 127 years from 1891 to 2018. Storm surge computed by IMD based on 50-year return data was adopted for the preparation of storm surge hazard layer. Both the layers were compared with the Building Material and Technology Promotion Council's (BMPTC) Vulnerability Atlas of India (2006) for conformity and classification. The flood hazard, compared to other hazards, was very difficult to compute on a wider geographical scale, thus it was extracted from the Bhuvan Geoportal where tile wise flood vulnerability index was computed based on multiple origin of floods (riverine, coastal, urban, flash flood and cyclonic floods).

The spatio-temporal characteristic of seismic activities was studied using the data sources of United States Geological Survey (USGS), Coastal Geodetic Survey (CGS), Amateur Seismic Centre (ASC) and IMD for Tamil Nadu and its surrounding regions from 1807 to 2018. Based on these datasets and BMPTC Vulnerability Atlas of India, the earthquake zones were delineated. Reported landslides and BMPTC Atlas were used to classify the landslides zones. Forest fire hazard map was prepared from the data extracted from Tamil Nadu Forest Department and MODIS satellite data.

All the generated hazard layers (earthquake, landslide, cyclone, storm surge, flood, drought, and forest fire) were reclassified into four levels of hazard,namely high, moderate, low, and nonhazard with a cell size of $250 \mathrm{~m}$. By utilising raster calculator tool in ArcGIS, all the hazard layers were intersected on a normalised scale and Multi Hazard Zones were prepared. Based on the combined intensity values, the Multi Hazard Zones were classified into four classes, namely very high, high, moderate, and low.

\section{Results and Discussion}

\subsection{Earthquake}

The spatio-temporal characteristic of seismic activities in Tamil Nadu shows concentration around Coimbatore, Madurai, Hosur, Salem, Shevaroy, Villupuram, Pondicherry, Chennai and Dharmapuri (Figure 2). The magnitude of the past earthquakes in the study area ranged from 3 to 6. It was observed that the earthquakes of maximum intensity 5-6 had occurred in the Coimbatore and surrounding Districts. Also,it was seen that the areas of maximum seismicity were also the ones that are densely populated. Whereas, in spite of the sparse distribution of seismic locations in Central and Western parts, the frequency tendedto be greater along with magnitude in the western parts in comparison to the Central part of the region.

\subsection{Drought}

The Scaled Drought Condition Index $(\mathrm{SDCI})$ is categorised into extreme drought $(<0.2)$, severe drought (0.2-0.3), moderate drought (0.3-0.4), abnormal dry (0.4-0.5), and no drought (>0.5). During the dry year (2016), about half of the State was witnessed the extreme drought. Severe drought (0.2 to 0.3) condition was observed in about 30 percent of the State. In 2016, the State was badly hit by the worst annual rainfall in 140 years as it received just $543 \mathrm{~mm}$ of rain against the annual average of $920 \mathrm{~mm}$. A weak La-Nina over the equatorial Pacific that followed a year of 
A. Balasundareshwaran et al / GEOSI Vol 5 No 1 (2020) 65-79

strong El-Nino was cited as one of the reasons for this drought. By considering drought condition during June to December in dry year (2016) and normalcy in base year (2007), the SDCI drought index was prepared as shown in Figure 3. The interior northern District of Tamil Nadu, such as Karur, Nammakal, Salem, Dindigul and Erode faced acute drought.

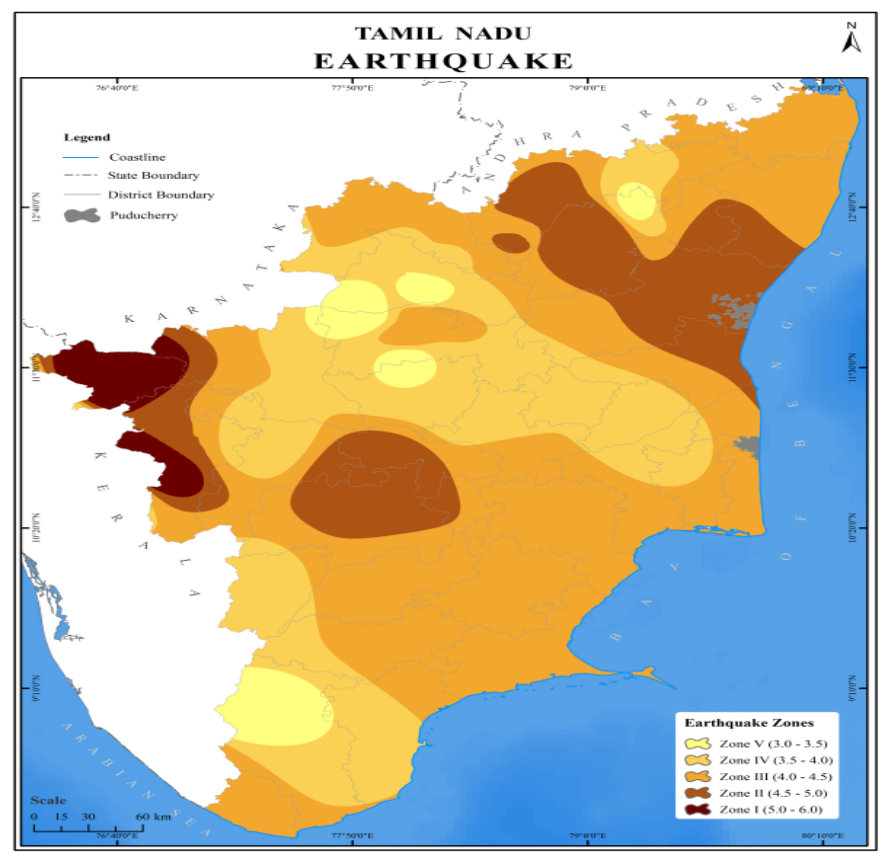

Figure 2. Earthquake zones in Tamil Nadu

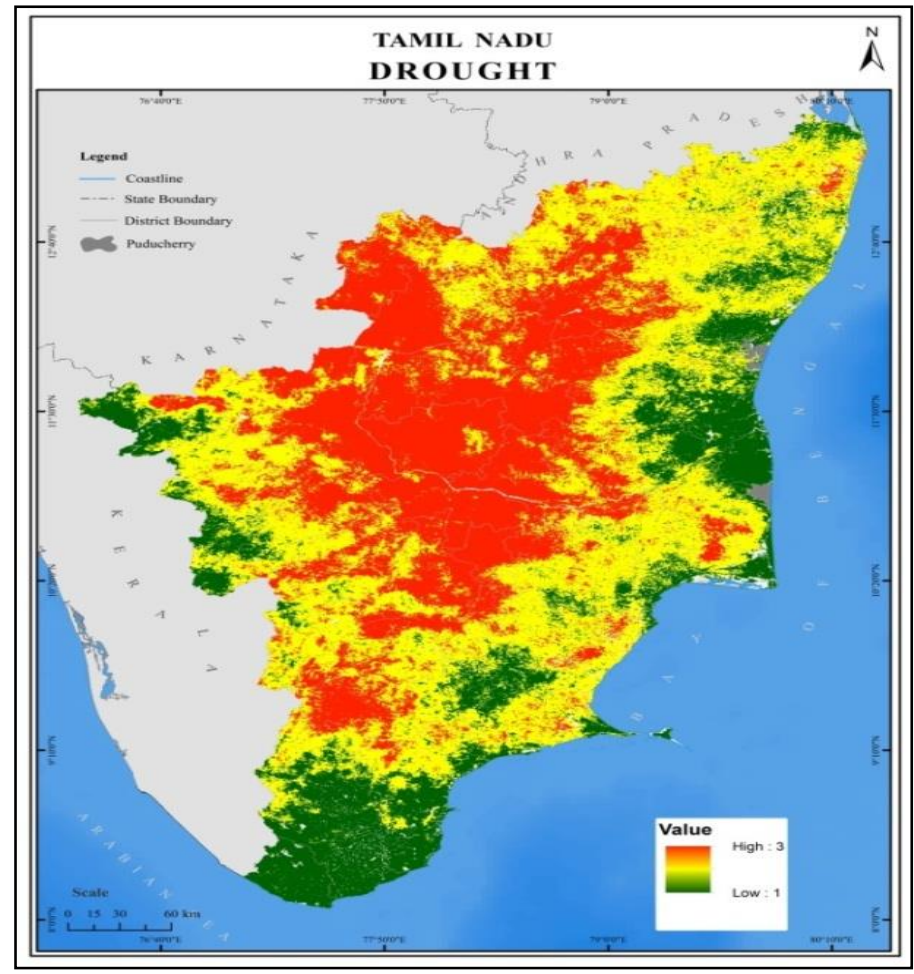

Figure 3. Scaled Drought Condition Index for Tamil Nadu 
A. Balasundareshwaran et al / GEOSI Vol 5 No 1 (2020) 65-79

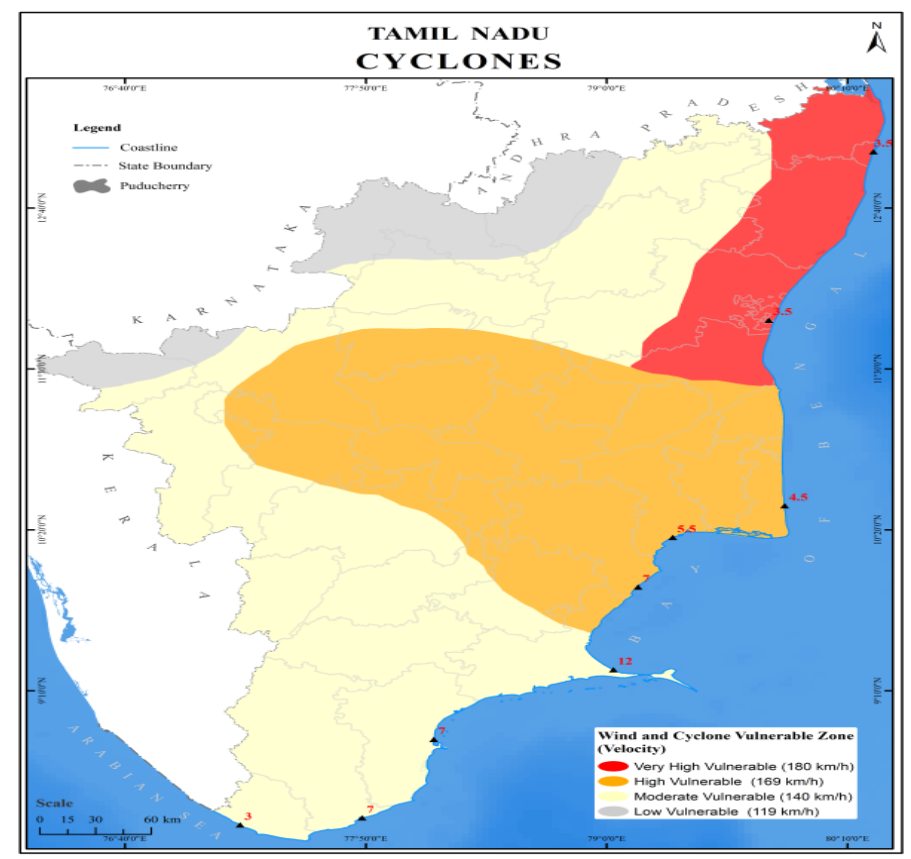

Figure 4.Cyclone zones in Tamil Nadu

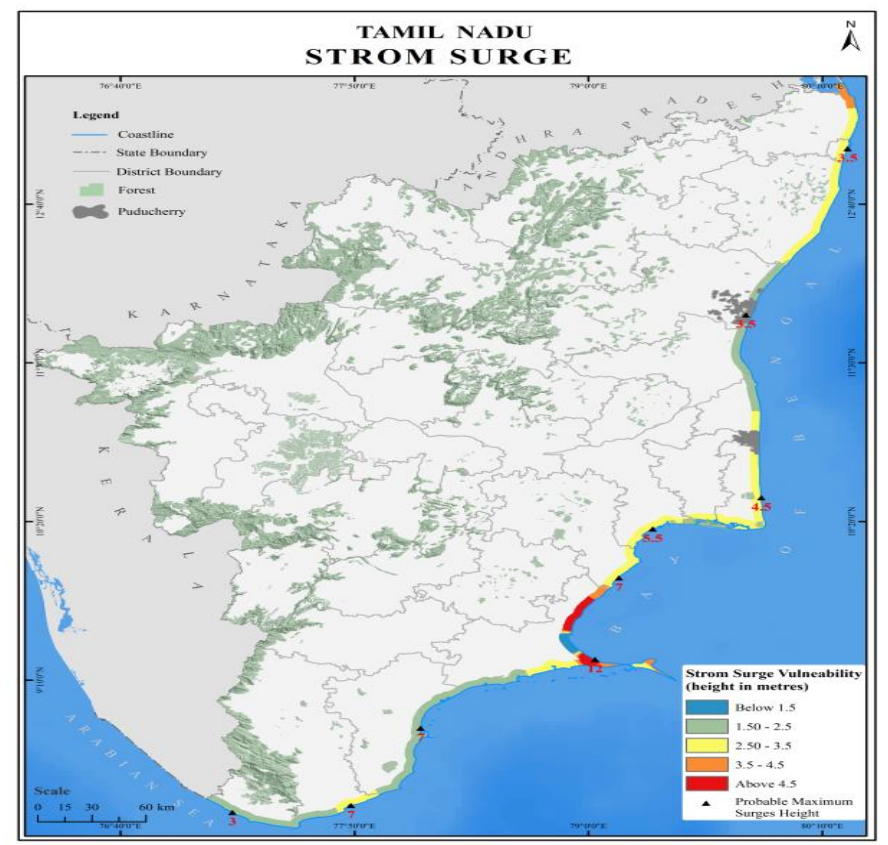

Figure 5. Storm Surge in coastal parts of Tamil Nadu

\subsection{Cyclone and Storm Surge}

The cyclone affecting Tamil Nadu are largely from Bay of Bengal. The very high hazard appeared in the northern coastal region of Tamil Nadu. The moderate zone was observed in central part of Tamil Nadu, extending as tongue from Cauvery delta. The November cyclones generally move west or north-westward and strike northern coasts of Tamil Nadu (Siddiki et al., 2012). The storm surge is often accompanied with the cyclone or sometimes with high wind, which affects the coastal margins, that vary up to $5 \mathrm{~km}$ from the coast (Figure 5). The hazard map shows a very high 
storm surge $(>4.5 \mathrm{~m})$ in Ramanathapuram District's coast. A high storm surge $(3.5-4.5 \mathrm{~m})$ was observed around Pulicat Lake (northern Tamil Nadu) which is understood for its tidal activities.

\subsection{Landslide}

The Western and Eastern Ghats of the State are prone to landslides. The severe up to very high class was observed in the steep slopes of the Western Ghats and very confined to the Nilgiris, Anamalai, Kodaikanal, Courtallam and Agasthyamalai hills. Eastern Ghat sections, especially Shayadri hills and Kolli hills,fell under high to moderate landslide hazard (Figure 6).

\subsection{Flood}

The flood hazard layer shows a combined effect of all flood events of Tamil Nadu that devastated settlements as well as vegetation. Flood vulnerability index for the whole Tamil Nadu is categorised into five classes, namely very high, high, moderate, low, and very low hazard zones (Figure 7). The flood vulnerability zone followed the deltaic regions of majorrivers of Tamil Nadu, especially between Palar to Cauvery deltaic region. The upper reaches of tributaries of Cauvery and Tamirabharani rivers were also found with very high hazard zones.

\subsection{Forest Fire}

The forest fire is highly concentrated in the Western and Eastern Ghats of the State where forest cover is intersected with settlements and transport lines (Figure 8). The forest fire occurred between 2006 and 2015 are classified into five classes of frequency; very low $(<4)$, low (5-9), moderate (10-14), high (15-19), and very high $(>20)$. The very high forest fire occurrences were at Mudumalai and Gundri in the east Kalvarayan, Jawathu, Kanamangalam, and Villapakkam in the west and northern parts of Tamil Nadu. A cluster of forest fires was observed at Valpari, Anamalai, Palani, Kodaikanal, and Agamalai hills at eastern central margins of Tamil Nadu and southern dense vegetation in Agasthyamalai hills.

\subsection{Multi-Hazard Zonation}

Multi-hazard zones reflect the complex nature of interaction between the hazards. It is very difficult to quantify the interaction but it can be relatively compared (Kappes et al., 2012). The natural hazards occur in the same location at different interval cause more damage than the location affected by a single hazard. The Multi-Hazard Zones (MHZ) sometimes are found with a domino effect, where one hazard triggers the next possible hazard, which is extremely dangerous. Hence, the assessment of $\mathrm{MHZ}$ is indispensable for disaster risk management and governance of critical time. Based on the interaction of all major natural hazards, MHZare delimited and classified into four classes, namely very high, high, moderate, and low (Figure 9). The very high MHZ is concentrated at hilly stretches of the Nilgiris and parts of Shayadhri hills in Coimbatore and Theni Districts. Further, the very high MHZ is found along the coastal stretch of Chennai, Kancheepuram, Cuddalore, and Ramanathapuram Districts. 
A. Balasundareshwaran et al / GEOSI Vol 5 No 1 (2020) 65-79
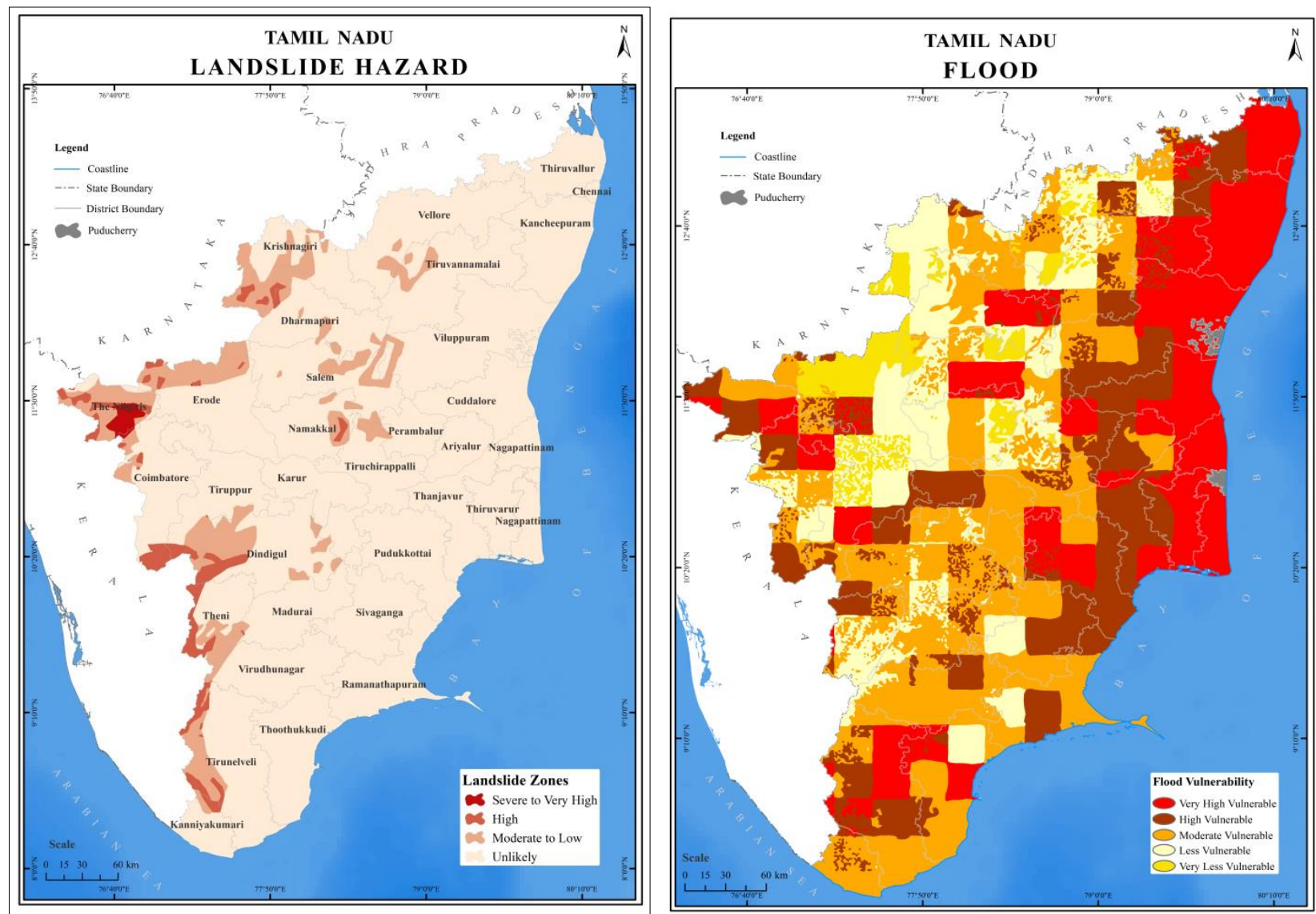

Figure 6. Landslides in Western and Eastern and Ghats of Tamil Nadu

Figure 7. Tiled Flood Index

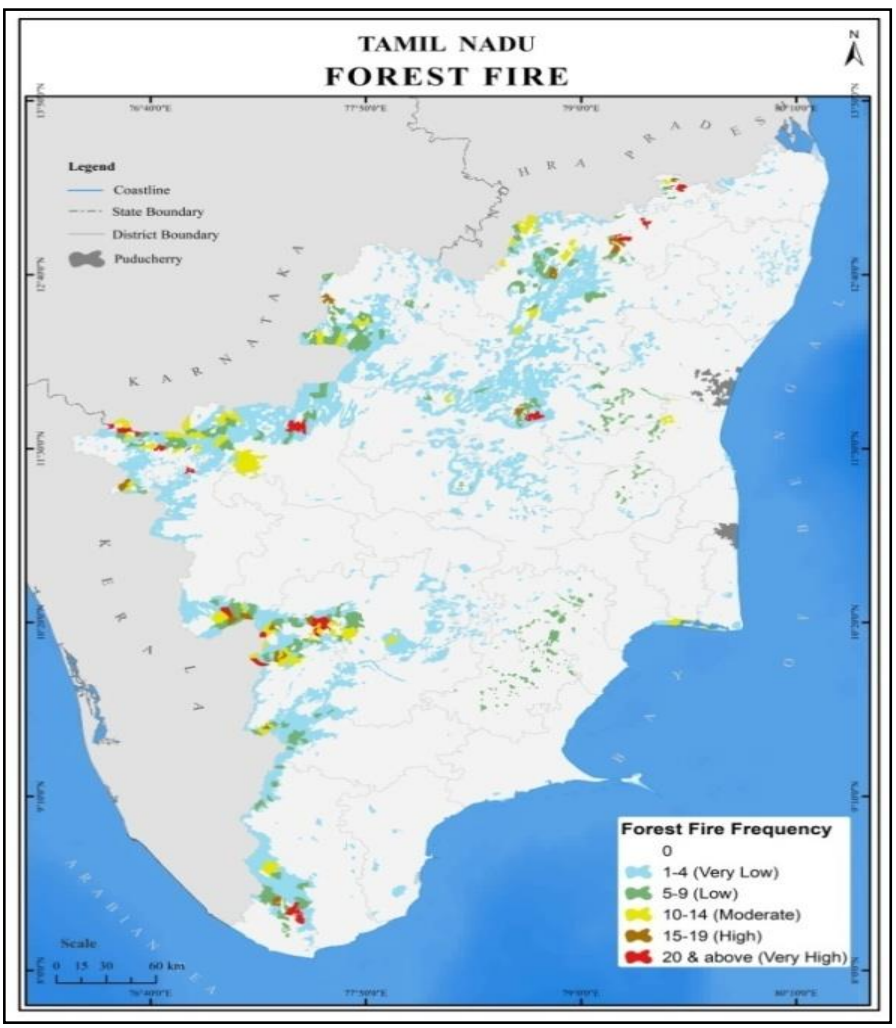

Figure 8. Forest Fire hazard in Tamil Nadu 
A. Balasundareshwaran et al / GEOSI Vol 5 No 1 (2020) 65-79

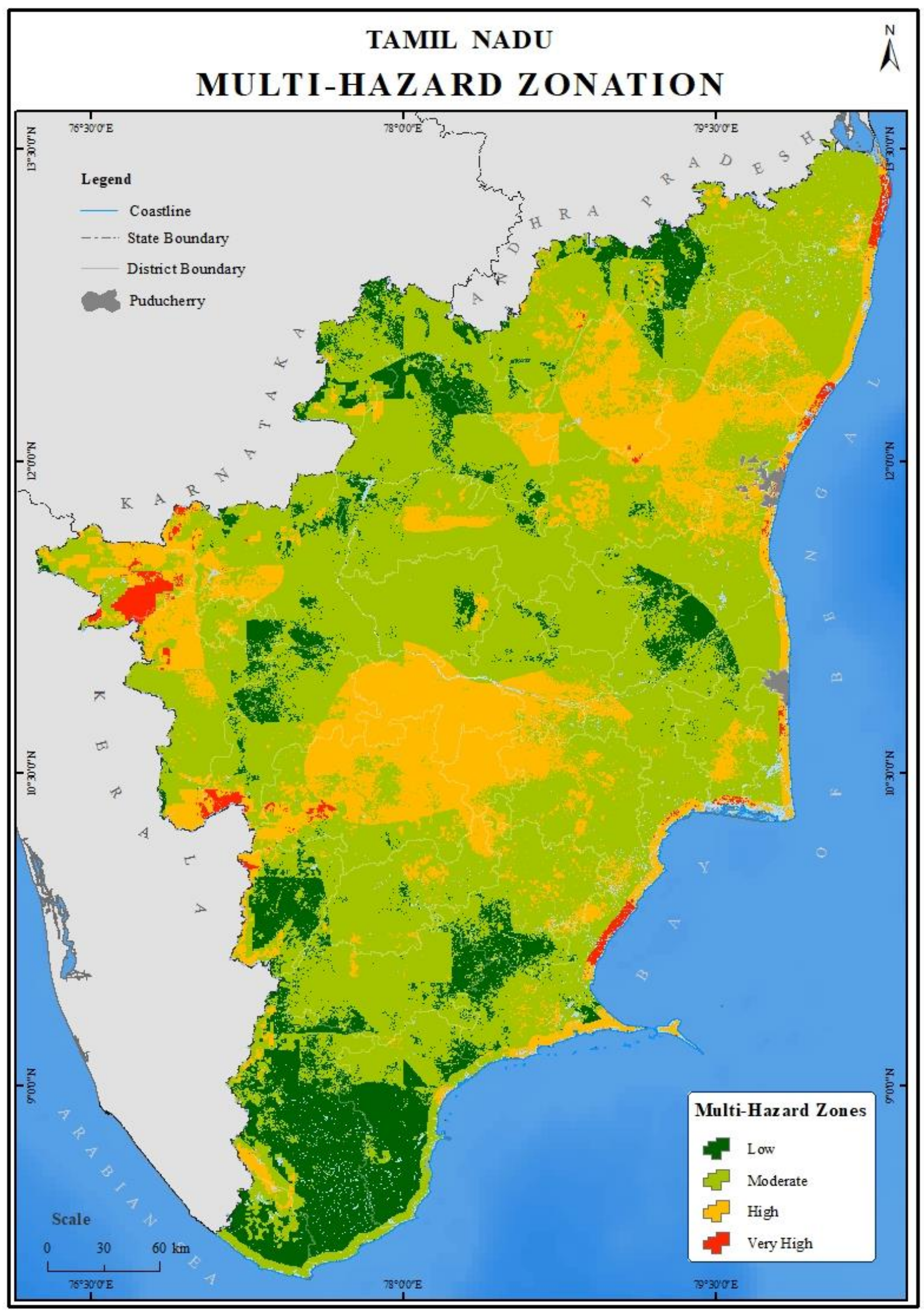

Figure 9. Multi-Hazard Zonation (MHZ) for Tamil Nadu 
A. Balasundareshwaran et al / GEOSI Vol 5 No 1 (2020) 65-79

The high MHZ is observed in the central regions of the State engulfing rest of the Nilgiris, Villupuram, Thiruvanamalai, Vellore and Karur Districts, and all along the central and northern coastal tracts of Tamil Nadu. The occurrences, intensities and frequencies of hazards, namely seismic, landslide and forest fire are the reasons for very high multi-hazard in the hilly tracts, whereas cyclone, storm surge and flood is the major reason for a very high risk along the coastal regions. The moderate MHZ vastly spreads over the rest of the State except for a few parts in the northern, eastern, and southern region where hazards with high intensities are absent. The moderate $\mathrm{MHZ}$ is the direct cause of higher intense of drought but moderate or low intense of cyclone and earthquake hazards.

The very high-to-high MHZ occurs in the western regions of hilly terrains, central plains, and the eastern margins of coastal regions. The result of this study coincides with case studies attempted for different parts of the State. For instance, agricultural drought assessment in Palar basin (Krishna et al., 2009) and drought condition over the Cauvery basin (Balasubramani, 2014) indicate similar prevalence of high MHZ at central and northeastern part of the State. The southern part of the Nilgirs falls under high and very high vulnerability as the area is under steep slope (Rahaman \& Aruchamy, 2017). Moreover, the fire risk assessment at Kurangani of Theni District forest debated by Balaguru et al., (2018) propose that the highly vulnerable zones falls at steep slopes and high altitude regions. Comparatively, a study on macrozonation of seismic hazard pursued by Menon et al., (2009) exhibits moderate vulnerability in northern and western parts of TN and much lower in the southern half of the state. The study also suggest that the hazard in the northwestern parts, some central districts of the State are clearly underestimated i.e., the hazard levels classified in seismic Indian Standard Zone III could be marginally higher, especially for Chennai, Coimbatore, Udhagamandalam, and Krishnagiri. These discussions support the very highto-high MHZ of western regions of hilly terrains and central plains of State. Similarly, the study on habitat risk assessment for coastal taluks of Tamil Nadu (Balasundareshwaran et al., 2019) reflects on the assessment of coastal vulnerability utilising the geospatial technology. The study implies the need of urgent measures to thwart negative impacts at Chennai, Cuddalore, Nagapattinam, Thoothukudi, and Agatheeswaram areas, which are highly vulnerable zones.

In the same way, the disaster risk management plan for Karur District attempted by Balasundareshwaran et al., (2019a) reveals that, during northeast monsoon, heavy water flowing in Cauvery and its tributaries, has affected the low-lying areas of the riverbanks with floods. The results of this present study show all the flood occurrences attributed to larger basins of Cauvery 
A. Balasundareshwaran et al / GEOSI Vol 5 No 1 (2020) 65-79

and Palar rivers. In an integrated study, classifying coastal Tamil Nadu (Rajan et al. 2019) reveals that the very high vulnerability zone covers Nagapattinam coast. Further, very high to high vulnerable zones cascade over Cuddalore, Kancheepuram Pondicherry, Karaikkal, Nagapattinam, and Thiruvarur. The physical vulnerability analysis conducted by Rajan and Vengadasalam (2019) along the coastal Tamil Nadu observed that coastal zone is still in underdeveloped condition. The study proposed that the Ramanathapuram District appears to be a better coast and Kancheepuram as a poor. Consequently, these deliberations correspond and represent the very high-to-high MHZ senario of coastal regions.

The major research gap exists in developing appropriate approaches to evolve disaster plans for the administrative units like districts. The hazards demarcated at the State level will be effective for planning at district and sub-district level planning and, thus, this study can be used as a pioneer material. The best use of geoinformatics in the digital era, especially in disaster scenarios, is very much needed, and the present work attempts to fulfil this gap.

\section{Conclusion}

This study is akin to a first-hand atlas to the planners and decision makers. The study combined different hazards and their intensities in a single map with varying intensities using the power of geoinformatics. These research highlights need for immediate and proper action plans at high multi-hazard prone zones. The very high MHZ is observed at the Nilgiris and parts of Shayadhri hills in Coimbatore and Theni Districts in the western region and along the coastal stretch of Chennai, Kancheepuram, Cuddalore, and Ramanathapuram Districts in eastern region of Tamil Nadu. The following recommendations are suggested for the very high -high MHZ of natural disasters of Tamil Nadu: (1) Identification and maintenance of the location specific disaster trigger based response system need to be given a higher priority, especially in the eastern hilly terrains and central plains; (2) Preparing region specific disaster management plans along with training for professionals / technical institutions to minimise the ill-effects for both administrative and natural regions, especially for the eastern coastal margins. This study offers scope for immediate knowledge, effective regionalisation, and possibilities of preparing disaster management plans. The segregation of results into administrative division's categorised in an order of highly risk zones will provide a power tool to the State authorities to allocate fund and resources. The further improvement of accuracy of certain datasets, e.g. flood, could precise the zonation and provide robust tool to prepare long-term plans for safeguarding the vulnerable communities, mitigating the physio-socio-economic losses, and attaining sustainable development 
A. Balasundareshwaran et al / GEOSI Vol 5 No 1 (2020) 65-79

\section{Conflict of Interest}

The authors declare that there is no conflict of interest with any financial, personal, or other relationships with other people or organizations related to the material discussed in the article.

\section{Acknowledgement}

The authors thank the Council of Scientific and Industrial Research - University Grant Commission (CSIR-UGC) and Indian Council of Social Science Research (ICSSR) for the financial support to complete the study. The authors also thank UGC-SAP-DRS-II Programme of the Department of Geography, Bharathidasan University, Tiruchirappalli for the infrastructural and technical supports.

\section{References}

Balaguru, M., Navammuniyammal, M., Vidhya, R. and Sathyavathi, G., (2018). Assessing Forest Fire Prone Area in Kurangani, Tamil Nadu using Remote Sensing and GIS. International Journal of Applied Engineering Research, 13(7), pp. 264-269

Balasubramani, K., (2014). "Assessing Vegetative Drought from Satellite Data: A Case Study of Cauvery Basin, South India". The Konkan Geographer, 8, pp.12-18.

Balasundareshwaran, A., Abdul Rahaman, S., Balasubramani, K., Kumaraswamy, K. and Ramkumar, M., (2019). "Habitat Risk Assessment Along Coastal Tamil Nadu”, India - An Integrated Methodology for Mitigating Coastal Hazards". Coastal Zone Management, pp. 515-542. doi.org/10.1016/B978-0-12-814350-6.00023-9

Balasundareshwaran, A., Kumaraswamy, K., Balasubramani, K. and Abdul Rahaman, S. (2019a). "Geoinformatics - Catalyst for Preparation of District Disaster Risk Management Plan: A Case of Karur District, Tamil Nadu”, Indian Geographical Journal, 94 (1), pp. 1-14.

Behanzin, I.D., Thiel, M., Szarzynski, J., and Boko, M., (2015). “GIS-based Mapping of Flood Vulnerability and Risk in the Benin Niger River Valley". International Journal of Geomatics and Geosciences, 6 (3), pp. 1653- 1668.

Bhanumurthy, V., Manjusree, P., and Srinivasa Rao, G., (2010). "Flood Disaster Management". Remote Sensing Applications, pp. 283-296.

Chigbu, N., Mbah, E. O., and Anyanwu, I., (2018). "Assessment of Flood Risk of Cross River State Using Geographic Information System (GIS)". Embracing Our Smart World Where the Continents Connect: Enhancing the Geospatial Maturity of Societies, Istanbul.

Gangai, P., Selvam, K. and Kumaraswamy, K., (2009). “A Spatio-Temporal Patterns of Earthquake Occurrences in South India”. Indian National Geographer, 24 (1), pp.48-54.

Hoque, M.A., (2017). "Cyclone Disaster Mapping, Monitoring and Management using Satellite Remote Sensing and Spatial Analysis". (Doctoral dissertation) https://espace.library.uq.edu.au

Kappes, M. S., Keiler, M., Von Elverfeldt, K., Glade, T., (2012). "Challenges of Analysing MultiHazard Risk: A Review”. Natural Hazards, 64 (2), pp. 1925-1958. 
Krishna, T.M., Ravikumar, G. and Krishnaveni, M., (2009). "Remote Sensing Based Agricultural Drought Assessment in Palar Basin of Tamil Nadu State, India”. Journal of the Indian Society of Remote Sensing, 37, pp.9-20. doi.org/10.1007/s12524-009-0008-8

Menon, A., Ornthammarath, T., Corigliano, M. and Lai, C.G. (2009). Probabilistic Seismic Hazard Macrozonation of Tamil Nadu in Southern India. Bulletin of the Seismological Society of America, 100(3), pp.1320-1341. doi.org/10.1785/0120090071

Natarajan, T.K., Murty, A.V.S.R., and Chandra, D., (1988). "Control of Surfacial Slides by Different Erosion Control Techniques". Proceedings 2". International Conference in Case Histories in Geotechnical Engineering, Rolla, 1, pp. 361-364.

NDMA, (2016). National Disaster Management Plan, GOI, Report.

Oluwasegun, A. H., (2017). "GIS Analysis of Flood Vulnerable Area in Benin-Owena River Basin Nigeria”, Indonesian Journal of Geography, 49 (1), pp. 27-33. doi.org/10.22146/ijg.12777

Prasad, N.N.R., and Narayanan, P., (2016). "Vulnerability Assessment of Flood-Affected Locations of Bangalore by Using Multi-Criteria Evaluation”, Annals of GIS, 22 (2), pp. 151-162, doi.org/10.1080/19475683.2016.1144649

Rahaman, S.A. and Aruchamy S., (2017). Geoinformatics Based Landslide Vulnerable Zonation Mapping Using Analytical Hierarchy Process (AHP), A Study of Kallar River Sub Watershed, Kallar Watershed, Bhavani Basin, Tamil Nadu. Modeling Earth Systems and Environment, 3 (1) pp.1-13. doi.org/10.1007/s40808-017-0298-8

Rajan S.M.P., and Vengadasalam R., (2019): SWOT and PCI based grading of coastal zone: A model emulation from Tamil Nadu Coast, India. Human and Ecological Risk Assessment: An International Journal. doi.org/10.1080/10807039.2019.1678382

Rajan S.M.P., Nellayaputhenpeedika M., Tiwari S.P. and Vengadasalam R., (2019): Mapping and analysis of the physical vulnerability of coastal Tamil Nadu. Human and Ecological Risk Assessment: An International Journal. doi.org/10.1080/10807039.2019. 1602752

Ramkumar, M., Santosh, M., Abdul Rahaman, S., BalaSundareshwaran, A., Balasubramani, K., Mathew, M. J., Sautter, B., Siddiqui, N., Usha, K. P., Sreerhishya, K., Prithiviraj, G., Nagarajan, R., Thirukumaran, V., Menier, D. and Kumaraswamy, K., (2019). "Tectonomorphological Evolution of the Cauvery, Vaigai, and Thamirabarani River Basins: Implications on Timing, Stratigraphic Markers, Relative Roles of Intrinsic and Extrinsic Factors, and Transience of Southern Indian Landscape", Geological Journal, pp.1-42. (ISSN: 0072-1050) doi.org/10.1002/gj.3520

Ramkumar, Mu., (2009). "Types, Causes and Strategies for Mitigation of Geological Hazards”, In: Ramkumar Mu., (Ed.) Geological Hazards: Causes, Consequences \& Methods of Containment. New India Publishing Agency, pp. 1-22.

Roy, D.C. and Blaschke, T., (2015). "Spatial Vulnerability Assessment of Floods in the Coastal Regions of Bangladesh", Geomatics, Natural Hazards and Risk, 6 (1), pp. 21-44. doi.org/10.1080/19475705.2013.816785

Shankar, V.S., Dharanirajan, K., and Narsimulu, G., (2015). "Cyclone Vulnerability Zonation of Southern Part of South Andaman, India Using Multi-Criteria Weighted Overlay Techniques", Indian Journal of Geo-Marine Sciences, 44 (8), pp. 1181- 1190. 
A. Balasundareshwaran et al / GEOSI Vol 5 No 1 (2020) 65-79

Sharma, S.V.S., Roy, P. S., Chakravarthi, V. and Rao, G., (2018). "Flood Risk Assessment Using Multi-Criteria Analysis: A Case Study from Kopili River Basin, Assam, India”. Geomatics, Natural Hazards and Risk, 9 (1), pp. 79-93. doi.org/10.1080/19475705.2017.1408705

Shrinarayan, J. N., (2015). "Study of Multi-hazards on Urban Habitats of India: A Case Study of Ahmedabad City", Thesis submitted to Gujarat Technological University, Ahmedabad.

Siddiki, U. R., Islam, M. N., and Aziz, M. N., (2012). "Cyclonic track analysis using GIS over the Bay of Bengal", International Journal of Applied Sciences and Engineering Research, 1(5), pp. 689-701. DOI: 10.6088/ijaser.0020101070.

Sofowote, U., and Dempsey, F., (2015). "Impacts of forest fires on ambient near-real-time PM2 in Ontario, Canada: Meteorological analyses and source apportionment of the July 2011-2013 episodes. Atmospheric Pollution Research, 6(1), 1-10.

Udani, P.M., and Mathur, D.K., (2016). "Flood Hazard Vulnerability Mapping Using Remote Sensing and GIS: A Case Study Along the Villages of Anand Taluka", Advances in Applied Science Research, 7 (3), pp. 214-221.

Udo, E.A., Ojinnaka, O.C., Baywood, C.N., and Gift. U.A., (2015). "Flood Hazard Analysis and Damage Assessment of 2012 Flood in Anambra State Using GIS and Remote Sensing Approach", American Journal of Geographic Information System, 4 (1), pp. 38-51.

UNDP (2012). "Disaster Risk Reduction Programme", United National Development Programme. (Date Accessed: 28/07/2018) https://www.in.undp.org/content/india/en/home/operations/projects/closed/goiundp_disaster riskreductionproject.html 